\title{
Saving two birds with one stone: solving the quandary of introduced, threatened species
}

Luke Gibson $^{1 *}$ and Ding Li Yong ${ }^{2}$

The international wildlife trade has spread numerous species across the planet and reduced populations of many of these same species in their native ranges. In some cases, the intentional or accidental release of traded organisms has led to the establishment of populations beyond their native ranges, in urban centers or adjacent wilderness and often with negative environmental consequences. Here, we describe examples of the conservation dilemma posed by introduced, threatened species and highlight ways to mitigate the threats presented by introduced populations - as well as the threats facing native populations - of the same species. Managing introduced populations - either by using them as substitutes to help offset the demand for wild-caught organisms or by translocating them in an effort to reinforce imperiled populations within their native ranges - represents a currently underutilized solution to two pressing conservation problems. Alternatively, naturalized populations could serve as research surrogates to facilitate an understanding of the natural history of the species in its native range. Such creative conservation strategies could help stem the continuing worldwide degradation of biodiversity.

Front Ecol Environ 2017; doi:10.1002/fee.1449

W ildlife trade constitutes one of the greatest threats to biodiversity (Sodhi et al. 2004; Rosen and Smith 2010; Bush et al. 2014). Intensive harvesting of species from the wild - destined for commercial markets - often leads to population declines, extirpations, and extinctions, even as targeted populations become rarer and more difficult to find (Courchamp et al. 2006; Harris et al. 2016). At the opposite end of the supply chain, markets where these species are sold are often the sources of introductions via deliberate or accidental releases (Carrete and Tella 2008). In some cases, introduced species might be declining in their native ranges while simultaneously establishing feral populations that - in their non-native

\section{In a nutshell:}

- The global extent of wildlife trade threatens many species with extinction

- International trade and deliberate translocations have introduced some of these threatened species to urban centers or other areas far from their natural ranges

- These introduced populations could be managed to provide a substitute for the supply of traded species, thereby curbing demand for wild populations

- Naturalized populations of introduced species could also be used in reintroduction efforts, to buffer declining populations of threatened species in their native ranges

${ }^{1}$ School of Biological Sciences, University of Hong Kong, Hong Kong, China*(lgibson@hku.hk); ${ }^{2}$ Fenner School of Environment and Society, The Australian National University, Canberra, Australia ranges - eventually threaten native species, habitats, or environmental processes.

We present well-documented examples of this increasingly pervasive conservation scenario and highlight possible solutions. To identify threatened species with wild populations established beyond their native distributions, we reviewed recent compilations (published after 2000) on feral species of terrestrial vertebrates (Lever 2003, 2005; Long 2003). We systematically searched for each species in these compilations using the International Union for Conservation of Nature (IUCN) Red List of Threatened Species (www.iucnredlist.org) to identify its current threat status, and included only those listed as Vulnerable (VU), Endangered (EN), or Critically Endangered (CR). Although biased toward amphibians, birds, mammals, and reptiles, our list also contains examples of invertebrates and plants, as well as unassessed species known to be in decline based on authoritative local sources or the gray literature. For all examined species, we verified the existence of non-native populations using published literature found on Google Scholar. Species that were introduced but have subsequently become extirpated in their non-native ranges were excluded from our analysis.

\section{Threatened species, introduced}

Many species that are threatened in their native ranges have been introduced elsewhere in the world, where, in some cases, they have thrived. The yellow-crested cockatoo (Cacatua sulphurea) has been subject to severe population declines in its native range in eastern 

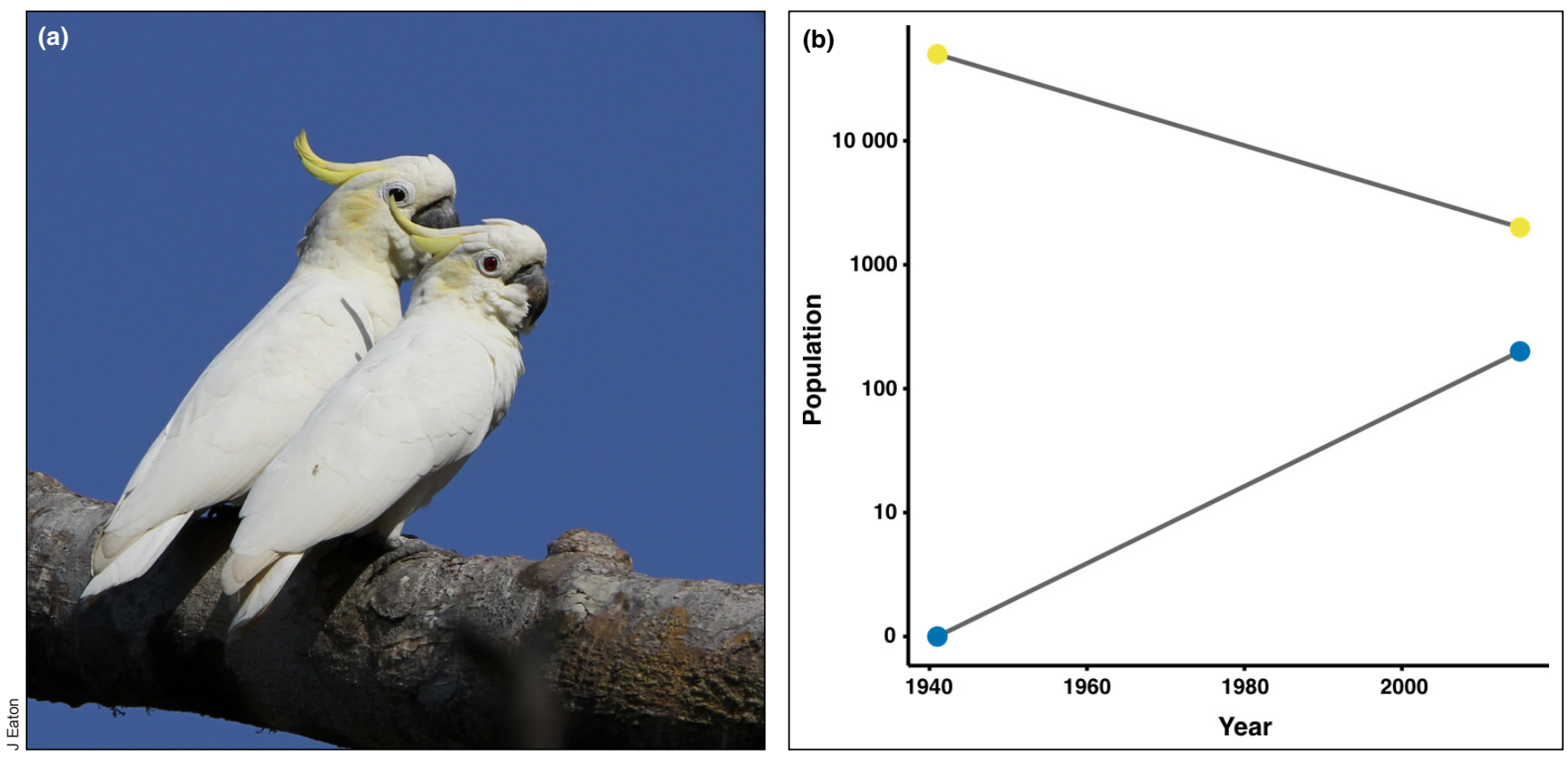

Figure 1. (a) Yellow-crested cockatoos (Cacatua sulphurea) in Komodo National Park, Indonesia. (b) Yellow-crested cockatoo population sizes ( $\log _{10}$ transformed) in its natural range (yellow circles) and in Hong Kong (blue circles), an introduced population. Trapping for international trade has greatly affected this Critically Endangered species in its native range in Indonesia and East Timor, where populations have plummeted from tens of thousands to just 1500-7000 individuals. Hong Kong's population, introduced in the mid-20th century, has risen into the hundreds and represents one of the largest populations globally.

Indonesia and East Timor, driven by domestic and international demand for pet birds (Figure 1; BirdLife International 2013a; Eaton et al. 2015). In May 2015, Indonesian police intercepted a shipment containing 23 of these Critically Endangered cockatoos, each individual stuffed inside a plastic bottle (Phillips 2015). Decades earlier, release of captive birds introduced this species to Hong Kong and Singapore, both important trade hubs in Asia that now sustain sizeable feral populations for a species otherwise threatened with extinction (Figure 1). These introduced cockatoos might cause damage to the few remaining large trees used by other resident species, and could also compete with native birds for nesting resources such as tree cavities (Leven and Corlett 2004).

Other threatened parrot species have established selfsustaining populations in urban centers or on islands far beyond their natural distribution (WebTable 1). In Singapore, following establishment by escaped or deliberately released cage birds, the red-breasted parakeet (Psittacula alexandri) now numbers over 500 individuals (Low and Owyong 2015). Increased trapping pressure has led to population reductions or even extirpations in its native range, and the species was recently uplisted to Near Threatened (BirdLife International 2013b). Singapore has experienced other introductions of exotic species to the detriment of its native fauna. The Javan myna (Acridotheres javanicus) was also introduced to Singapore through captive releases, with populations now exceeding 100,000 and possibly causing population declines of the native oriental magpie robin (Copsychus saularis; Lim et al. 2003). This myna - a starling species has been extensively trapped for the cage bird trade, and populations in its native range in Java have collapsed (Eaton et al. 2015) to the point that it is now considered Vulnerable (BirdLife International 2016).

Populations of threatened species - particularly ungulates - have also been introduced in non-urban areas. These populations of introduced ungulates were founded by individuals that either escaped from farms or were intentionally released to establish populations for hunting (Fraser et al. 2000). A population of Endangered banteng (Bos javanicus) introduced to Australia is now larger than the combined native populations of banteng in Southeast Asia (Figure 2; Bradshaw et al. 2006). The Vulnerable Philippine deer (Rusa marianna), first described based on introduced populations still present in the Mariana Islands and Guam, persists in highly fragmented forest habitats within its natural range in the Philippine archipelago, where it continues to suffer population losses under hunting pressure (MacKinnon et al. 2015). Nonnative Barbary sheep (Ammotragus lervia) and mouflon (Ovis orientalis) - both listed as Vulnerable - number in the hundreds in the Canary Islands, where they compete with native Iberian ibex (Capra pyrenaica) and threaten dozens of endemic plant species (Garzón-Machado et al. 2012). Paradoxically, most of these ungulate species were introduced beyond their native ranges for game hunting and are now primarily threatened by hunting within their native ranges (WebTable 1). Future translocation of 

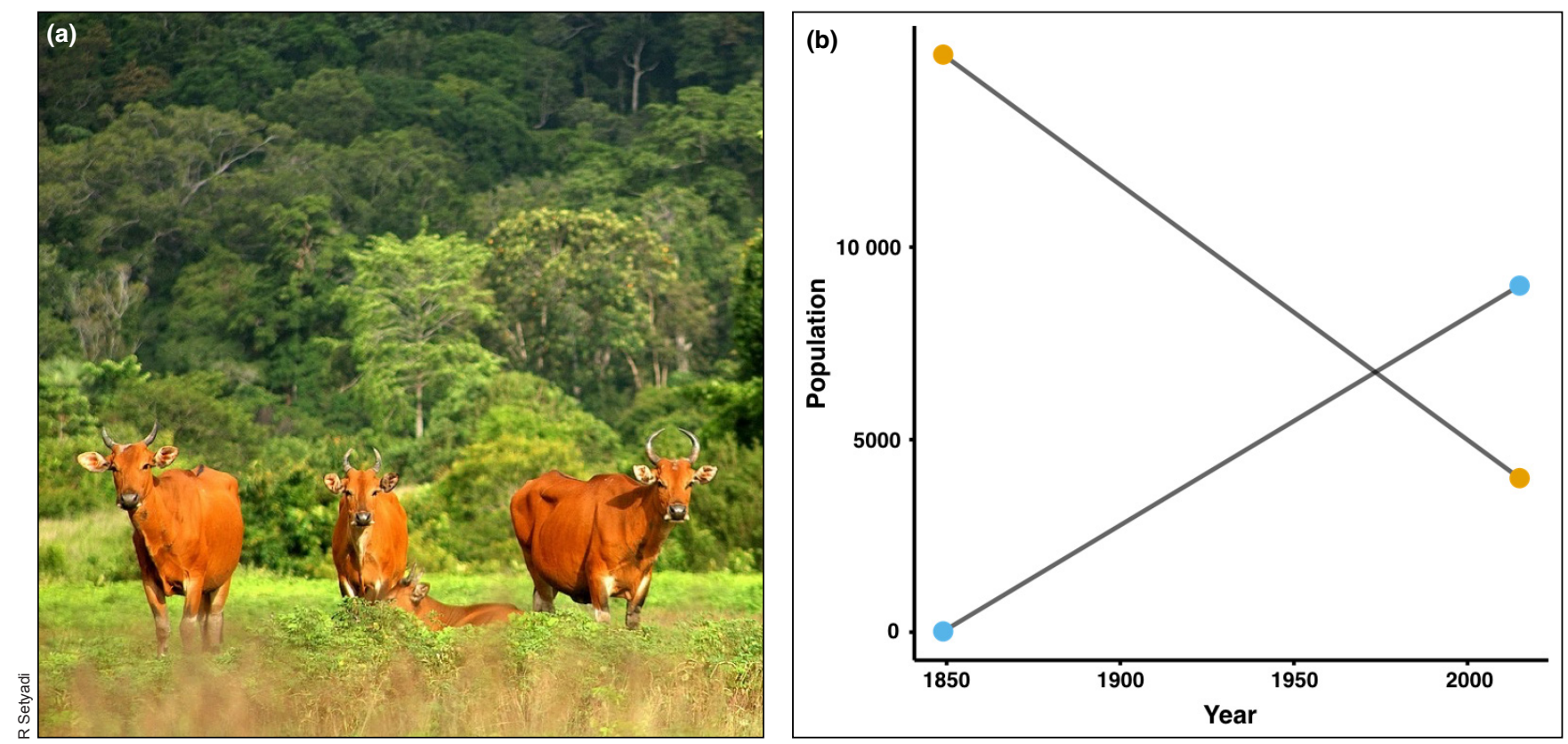

Figure 2. (a) Bantengs (Bos javanicus) in Alas Purwo National Park, Java, Indonesia. (b) Banteng population sizes in its native range (orange circles) and in Northern Territory, Australia (light blue circles), where it was introduced in 1849. From just 20 individuals, Australia's introduced population has risen to near 10,000 individuals, exceeding the population in its entire native range throughout Southeast Asia, where the species is classified as Endangered due to hunting and habitat loss.

these introduced populations could potentially buffer declining populations in their native ranges while simultaneously reducing threats to native species in their introduced ranges.

These cases are not limited solely to birds and mammals (WebTable 1 and Figure 3). Two species of bell frogs (Litoria aurea and Litoria raniformis), intentionally introduced in the late 19th century and now widespread in New Zealand, are experiencing population declines in their native ranges in Australia, where they are listed as Vulnerable and Endangered, respectively (Bishop 2008). On the islands of Mauritius and Hawaii, introduced populations of the wattle-necked softshell turtle (Palea steindachneri) - listed as Endangered in its native range within China and Vietnam because of its use as a traditional food - now require protection, which is "critical for the survival of the species" (Asian Turtle Trade Working Group 2000). As the largest introduced predator in Hawaii's freshwater ecosystems, $P$ steindachneri has altered the food web and might have led to declines of endemic fish species (Marchetti and Engstrom 2016). Invasive populations of Burmese pythons (Python bivittatus) are causing population crashes of native mammal species in the Florida Everglades (McCleery et al. 2015), while native populations of pythons in Southeast Asia are undergoing precipitous declines due to harvest for its skin, for medicine, and for the pet trade (Stuart et al. 2012). The diversity of taxa subject to similar scenarios (WebTable 1 and Figure 3), in addition to the geographic extent involved, highlights the scale of the problem facing conservation practitioners.

\section{Solutions}

These populations of species - imperiled in their native ranges but posing threats in their introduced ranges - offer a unique opportunity to consider an integrated conservation approach that accounts for both circumstances. Reintroduction of introduced populations to their native ranges could buffer populations exploited by the wildlife trade while at the same time diminishing possible threats to native species in their introduced ranges. However, the science of species reintroduction is still poorly developed and precautions must be taken to ensure that reintroductions are properly and effectively implemented (Figure 4). Others have highlighted key criteria to evaluate reintroduction efforts (eg Kleiman 1989; Seddon et al. 2007; Armstrong and Seddon 2008), which we will not repeat here. Instead, we list examples of threatened species that have reestablished populations in their original ranges via translocations from populations introduced elsewhere.

\section{Captive breeding}

The establishment of a captive breeding facility - used to restock declining native populations - is traditionally one of the first steps in the conservation of imperiled species. As populations of golden-headed lion tamarins (Leontopithecus chrysomelas) gradually disappeared due to habitat loss and fragmentation in the highly degraded Atlantic Forests of Bahia, Brazil, a captive breeding 
program was established for the species at the Rio de Janeiro Primate Center, founded using animals originating from illegal trade in the 1980s (Kierulff et al. 2008). Since then, an accidental release by a private collector has introduced the species to the suburbs of Rio de Janeiro. Growing numbers in its introduced range ( $>100$ in 2009) could threaten its native relative, the golden lion tamarin (Leontopithecus rosalia), either by hybridization between the two Endangered species or by spread of infectious disease (Kierulff 2010). To counteract this threat, the introduced $L$ chrysomelas population could be trapped to augment the captive population in order to increase the facility's capacity and boost genetic diversity. However, before such action is taken, it is imperative to ensure that the introduced population has not contaminated its genetic pool by interbreeding with its native congeneric, and that it does not harbor any parasites or diseases that could be transmitted to other individuals at the captive breeding facility (Figure 4). If members of captive populations are destined for future reintroductions, the possibility of genetic adaptation to captivity (Christie et al. 2012) should also be considered.

\section{Reintroduction}

Reintroduction programs drawing from introduced populations could potentially eliminate threats posed to endemic biodiversity and augment diminishing native populations of these species. Although feasible, such efforts should not be pursued until populations in their native ranges are first better studied and receive improved protection, through habitat preservation and antipoaching efforts (Rocha and Bergallo 2012). While in captivity, animals selected for reintroductions should also be screened for diseases or parasites and checked for genetic hybridization with closely related species through careful pedigree analysis, in order to avoid contamination of native populations (Figure 4; Kierulff 2010). After meeting these requirements, such populations could serve as a viable "ark" for future conservation intervention, which could help to restore defaunated communities around the world (Dirzo et al. 2014) and offer an additional source of genetic diversity for native (and potentially inbred) wild populations (Ochoa et al. 2016).

There are rare examples of successful reintroductions originating from naturalized populations. The Arabian oryx (Oryx leucoryx), before it was exterminated in the wild by poaching, was captured for captive breeding programs in the US and parts of the Arabian Peninsula. Reintroductions in the 1980s and 1990s - comprising a total of 40 individuals - contributed to the reestablishment of this species in its native range in the Arabian Desert, where populations grew to approximately 400 individuals by the mid-1990s (Spalton et al. 1999). Unfortunately, resumption of poaching for trade of live animals has decimated this reintroduced population, which today is no longer considered viable. Over a decade's worth of progress

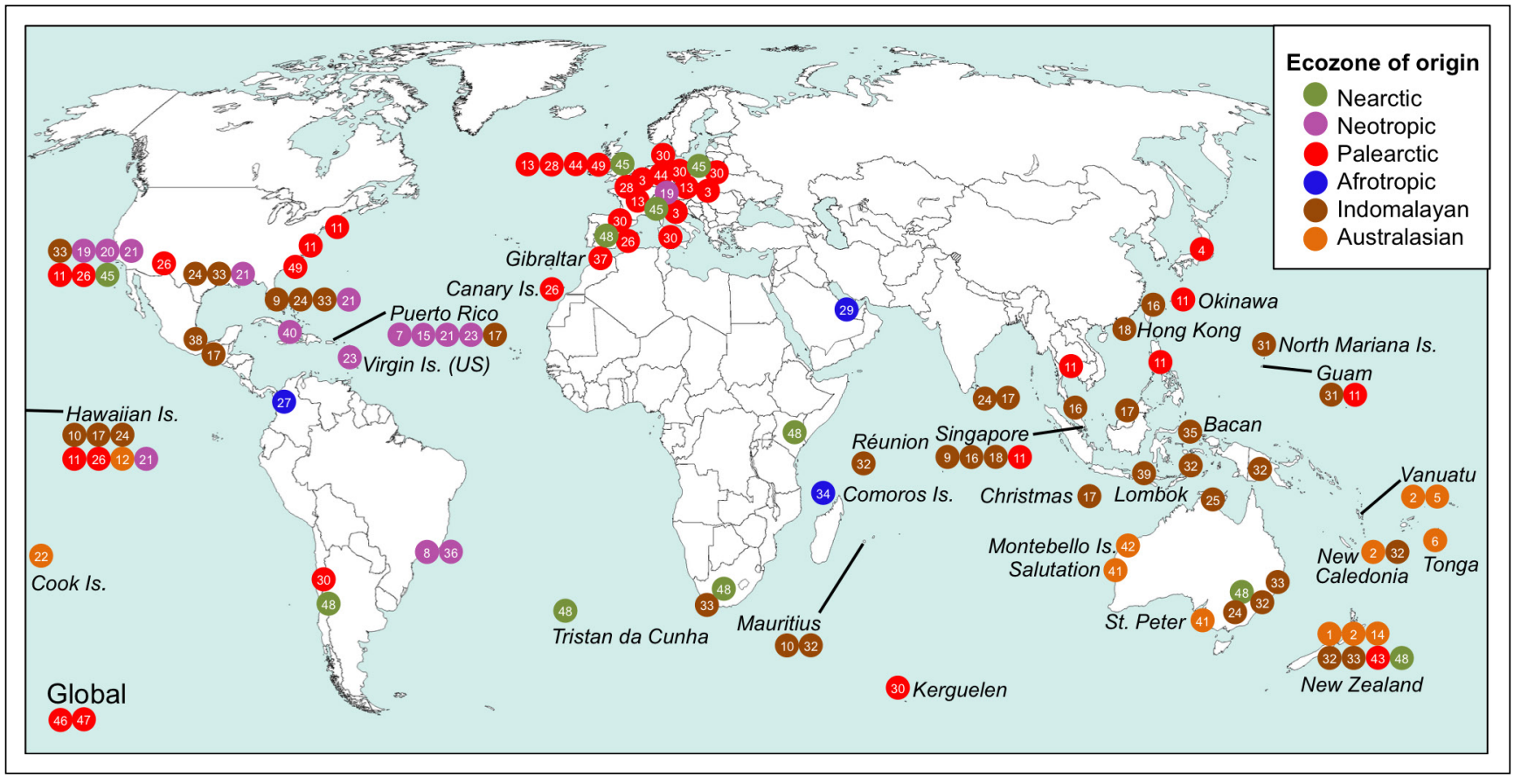

Figure 3. Map showing introduced and now naturalized populations of animal and plant species across the world now listed as threatened (VU, EN, CR) under IUCN criteria. Species are color coded by their regions of origin (see legend inset); numbers refer to different species listed in WebTable 1. Widely introduced species (Lotus maculatus [46] and Ginkgo biloba [47]) appear at the bottom-left corner to reflect their global distribution. 
through intensive conservation efforts was abruptly reversed because of this shift in threats within the oryx's native range.

Another ungulate, Père David's deer (Elaphurus davidianus), was nearly driven to extinction, largely due to hunting, over a century ago. However, in the late 1800s, the species was introduced to private collections in Europe, which have since been used to reestablish populations in its native range in eastern China (Jiang et al. 2000). Reintroduction efforts commenced in 1985 and have since bolstered wild populations, which number around 2000 animals (Zhigang and Harris 2008). This species' native population is apparently limited by the availability of habitat, most of which has been converted into agricultural lands. Now, all introduced populations of Père David's deer outside its native range are held within zoos, and we have therefore excluded it from our table of introduced threatened populations.

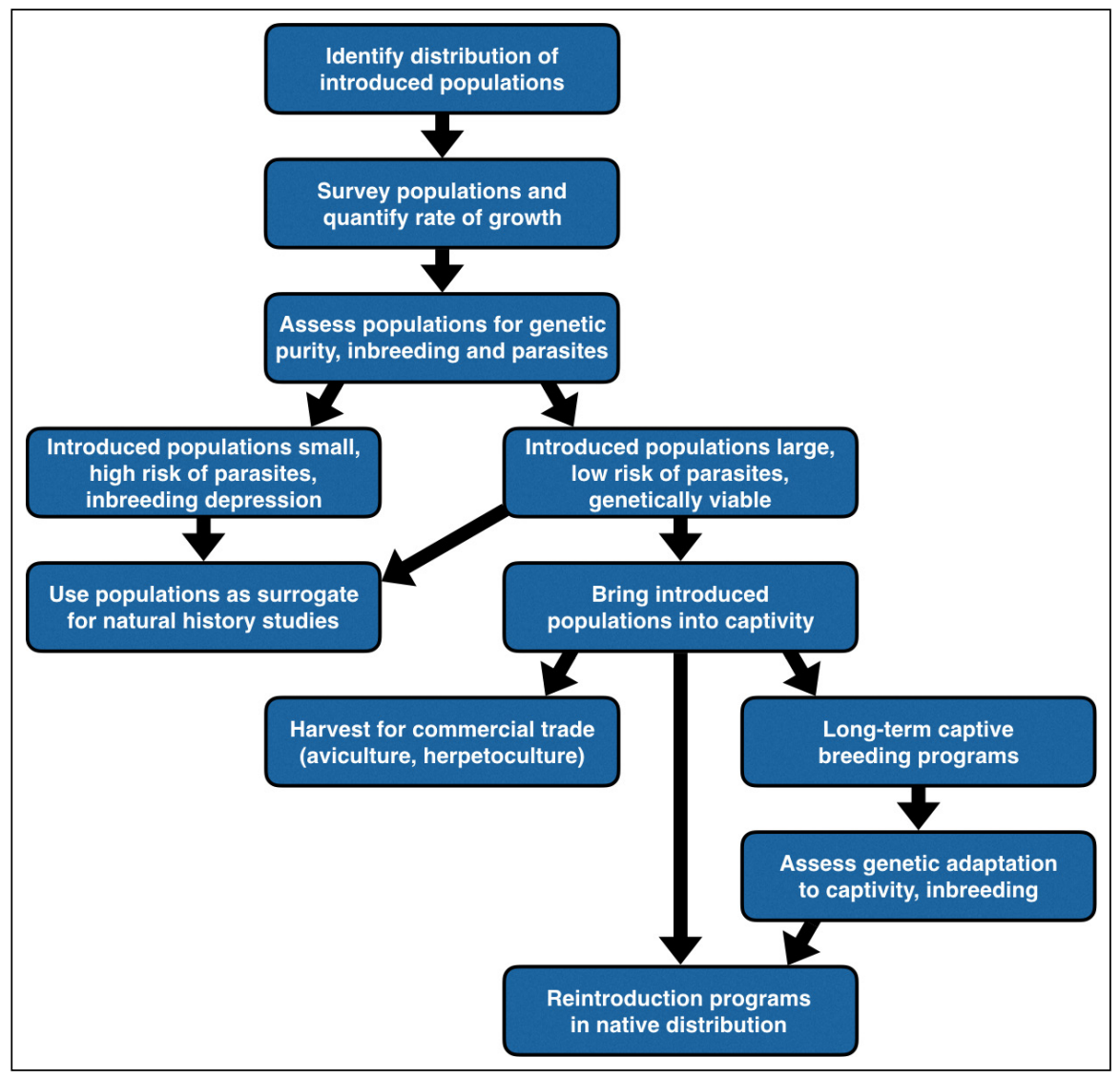

Figure 4. Flowchart showing key decision points in utilizing naturalized populations for conservation measures, either by means of captive breeding, reintroduction, research, or harvest for wildlife trade.

\section{Research}

If naturalized populations within a species' introduced range are too small or vulnerable for reintroduction via captive breeding, there are other available options - including use of the populations as research surrogates, to help guide conservation efforts. The Endangered Mariana swiftlet (Aerodramus bartschi), endemic to Guam and the Northern Mariana Islands, is threatened by habitat loss and predation by the invasive brown tree snake (Boiga irregularis) on Guam and Saipan (Cruz et al. 2008). This swiftlet was deliberately introduced to Oahu, Hawaii, where it later established a small population. The Hawaiian population has proved to be a useful surrogate for research into the ecology and natural history of the species and has been the focus of intensive study in recent years (eg Wiles and Woodside 1999), thereby facilitating conservation efforts targeting the swiftlet in its native range (Johnson 2015).

Another example of a research surrogate comes from the Atlas Mountains spanning Algeria and Morocco, where the native Barbary macaque (Macaca sylvanus) has experienced population declines caused by poaching for the pet trade. This Endangered species has established an introduced population in Gibraltar, where approximately 200 macaques exist (Butynski et al. 2008). Studies on this introduced population have contributed to the know- ledge of the species and its interactions with humans (eg Schurr et al. 2012).

\section{Harvest}

Animals from introduced populations could also possibly be managed for harvest, so as to alleviate pressures on wild populations as a result of hunting or habitat loss. The Cuban iguana (Cyclura nubila) is a Vulnerable species that has a thriving population on Isla Margueyes off Puerto Rico, where it was introduced (Christian 1986). Besides functioning as a surrogate for ecological research (Martins and Lamont 1998), this naturalized population has also been exploited by the herpetoculture industry and it is now thought that every $\mathrm{C}$ nubila individual in herpetoculture today originated from this introduced population (Crutchfield 2014).

Harvesting individuals from introduced populations of highly desired species - such as the Endangered Java sparrow (Padda oryzivora) and red siskin (Carduelis cucullata) or the Vulnerable Javan myna - can offer an alternative supply for the pet trade, thereby moderating hunting pressures faced by their imperiled wild counterparts. Sustainable trade of these introduced populations could provide a viable substitute for the capture of wild individ- 
uals, which is depleting populations in their native ranges. However, conservationists must consider the risk of elevating demand and poaching of native populations that might result from the harvest of introduced populations (Kirkpatrick and Emerton 2010). Only in those scenarios where non-native harvest does not elevate risks posed to native populations should this solution be considered (Tensen 2016).

\section{Conclusions}

The "conservation paradox" caused when threatened species become naturalized beyond their native ranges is already widespread (WebTable 1; Marchetti and Engstrom 2016). The IUCN Red List (version 2015.4, www.iucnredlist.org) currently lists 1399 species as threatened (VU/EN/CR); of these, 836 (almost 60\%) are imperiled at least partly by biological resource use (eg hunting and trapping of animals, gathering of plants for commercial trade). As the trade of threatened species continues to move wild animals between natural habitats and urban centers, such cases will become even more prevalent and conservation practitioners will likely need to address challenges raised by wildlife trade more frequently. Our review draws attention to this phenomenon, which contrasts with global species declines resulting from habitat loss and harvest for the pet trade. Many of these introduced populations could become useful for the conservation of the species if conservationists can formulate robust strategies that take advantage of these populations as subjects of ex situ conservation projects, reintroduction, or long-term studies of a species' ecology, and thus controlling the species' non-native populations in the long term.

While we acknowledge the usefulness of populations of some introduced species for conservation efforts, this should be carefully evaluated by conservationists and should not be taken to indicate broad support for maintaining populations of introduced species. There is a large body of empirical evidence illustrating the negative effects of introduced species in their non-native distributions (eg Simberloff et al. 2013). Introduced species can affect native species through predation or competition, and can even drive trophic cascades that affect entire host ecosystems, such as in the case of the wattle-necked softshell turtle (Marchetti and Engstrom 2016). It is therefore in the interest of maintaining functional native ecosystems to manage and, if resources permit, carefully remove populations of these introduced species, but with due consideration for the broader ecosystem context (Zavaleta et al. 2001). In two of our proposed scenarios, where the introduced population is harvested as an alternative supply for the pet trade, or used as a potential source for reintroduction efforts, the pressure exerted by these non-native populations could be kept in check, thus mitigating impacts on native species in the host ecosystem.
As many species disappear from their native ranges while thriving in other parts of the world where they have been introduced, we urge conservationists to explore innovative approaches to protect species. In several cases, by using introduced populations as a source for reintroductions to their native range where the species is in decline, a win-win scenario could be achieved in both ranges, which might help optimize use of the limited funding currently available to biodiversity conservation.

\section{Acknowledgements}

We thank H Cahyono, A Klegarth, J Lee, A Low, E Pickett, R Steinmetz, C Trainor, and K Yordan for useful discussions on this subject. LG thanks the World Future Foundation for support. DLY thanks the Lesslie Foundation for support.

\section{References}

Armstrong DP and Seddon PJ. 2008. Directions in reintroduction biology. Trends Ecol Evol 23: 20-25.

Asian Turtle Trade Working Group. 2000. Palea steindachneri. The IUCN Red List of Threatened Species, version 2015.2. www. iucnredlist.org. Viewed 29 Nov 2016.

BirdLife International. 2013a. Cacatua sulphurea. The IUCN Red List of Threatened Species, version 2015.2. www.iucnredlist. org. Viewed 29 Nov 2016.

BirdLife International. 2013b. Psittacula alexandri. The IUCN Red List of Threatened Species, version 2015.2. www.iucnredlist. org. Viewed 29 Nov 2016.

BirdLife International. 2016. Acridotheres javanicus. The IUCN Red List of Threatened Species, version 2016.3. www.iucnred list.org. Viewed 8 Dec 2016.

Bishop PJ. 2008. Bell frog populations in New Zealand - good news or bad news? Aust Zool 34: 408-13.

Bradshaw CJA, Isagi Y, Kaneko S, et al. 2006. Conservation value of non-native banteng in Northern Australia. Conserv Biol 20: 1306-11.

Bush ER, Baker SE, and MacDonald DW. 2014. Global trade in exotic pets 2006-2012. Conserv Biol 28: 663-76.

Butynski TM, Cortes J, Waters S, et al. 2008. Macaca sylvanus. The IUCN Red List of Threatened Species, version 2015.2. www. iucnredlist.org. Viewed 29 Nov 2016.

Carrete M and Tella JL. 2008. Wild-bird trade and exotic invasions: a new link of conservation concern? Front Ecol Environ 6: 207-11.

Christian K. 1986. Aspects of the life history of Cuban iguanas on Isla Magueyes, Puerto Rico. Caribbean J Sci 22: 159-64.

Christie MR, Marine ML, French RA, and Blouin MS. 2012. Genetic adaptation to captivity can occur in a single generation. P Natl Acad Sci USA 109: 238-42.

Courchamp F, Angulo E, Rivalan P, et al. 2006. Rarity value and species extinction: the anthropogenic Allee effect. PLoS Biol 4: e415.

Crutchfield T. 2014. Cuban rock iguana care tips. Reptile Magazine. www.reptilesmagazine.com/Lizards/Cuban-Rock-Iguana-CareTips. Viewed 29 Nov 2016.

Cruz JB, Kremer SR, Martin G, et al. 2008. Relative abundance and distribution of Mariana swiftlets (Aves: Apodidae) in the Northern Mariana Islands 1. Pacific Sci 62: 233-46.

Dirzo R, Young HS, Galetti M, et al. 2014. Defaunation in the Anthropocene. Science 345: 401-06. 
Eaton JA, Shepherd CR, Harris JBC, et al. 2015. Trade-driven extinctions and near-extinctions of avian taxa in Sundaic Indonesia. Forktail 31: 1-12.

Fraser KW, Cone JM, and Whitford EJ. 2000. A revision of the established ranges and new populations of 11 introduced ungulate species in New Zealand. J Roy Soc New Zeal 30: 419-37.

Garzón-Machado V, del-Arco-Aguilar MJ, and Pérez-de-Paz PL. 2012. Threat or threatened species? A paradox in conservation biology. J Nat Conserv 20: 228-30.

Harris JBC, Tingley MW, Hua F, et al. 2016. Measuring the impact of the pet trade on Indonesian birds. Conserv Biol; doi:10.1111/ cobi.12729.

Jiang Z, Yu C, Feng Z, et al. 2000. Reintroduction and recovery of Père David's deer in China. Wildlife Soc B 28: 681-87.

Johnson NC. 2015. Population ecology of the Mariana swiftlet (Aerodramus bartschi) on O'ahu, Hawaiian Islands (MS thesis). Corvallis, OR: Oregon State University.

Kierulff MCM. 2010. Invasive introduced golden-headed lion tamarins - a new threat to golden lion tamarins. Tamarin Tales 10: $5-7$.

Kierulff MCM, Rylands AB, Mendes SL, and de Oliveira MM. 2008. Leontopithecus chrysomelas. The IUCN Red List of Threatened Species, version 2015.2. www.iucnredlist.org. Viewed 29 Nov 2016.

Kirkpatrick RC and Emerton L. 2010. Killing tigers to save them: fallacies of the farming argument. Conserv Biol 24: 655-59.

Kleiman DF. 1989. Reintroduction of captive mammals for conservation. BioScience 39: 152-61.

Leven MR and Corlett RT. 2004. Invasive birds in Hong Kong, China. Ornithol Sci 3: 43-55.

Lever C. 2003. Naturalized reptiles and amphibians of the world. Oxford, UK: Oxford University Press.

Lever C. 2005. Naturalised birds of the world. London, UK: T \& AD Poyser.

Lim HC, Sodhi NS, Brook BW, and Soh MCK. 2003. Undesirable aliens: factors determining the distribution of three invasive bird species in Singapore. J Trop Ecol 19: 685-95.

Long JL. 2003. Introduced mammals of the world: their history, distribution and influence. Collingwood, Australia: CSIRO Publishing.

Low A and Owyong A. 2015. 5th annual parrot count 2015. Nature News (Singapore) May-June: 8-9.

MacKinnon JR, Ong P, and Gonzales JC. 2015. Rusa marianna. The IUCN Red List of Threatened Species, version 2015.2. www.iucnredlist.org. Viewed 29 Nov 2016.

Marchetti M and Engstrom T. 2016. The conservation paradox of endangered and invasive species. Conserv Biol 30: 434-37.

Martins EP and Lamont J. 1998. Evolution of communication and social behavior: a comparative study of Cyclura rock iguanas. Animal Behav 55: 1685-706.
McCleery RA, Sovie A, Reed RN, et al. 2015. Marsh rabbit mortalities tie pythons to the precipitous decline of mammals in the Everglades. Proc R Soc B 282: 20150120

Ochoa A, Wells SA, West G, et al. 2016. Can captive populations function as sources of genetic variation for reintroductions into the wild? A case study of the Arabian oryx from the Phoenix Zoo and the Shaumari Wildlife Reserve, Jordan. Conserv Genet 17: $1145-55$

Phillips T. 2015. Critically endangered cockatoos stuffed into plastic bottles by Indonesia smugglers. The Telegraph. May 5 . http://bit.ly/1GYgA8c. Viewed 29 Nov 2016.

Rocha CFD and Bergallo HG. 2012. When invasive exotic populations are threatened with extinction. Biodivers Conserv 21: 3729-30.

Rosen GE and Smith KF. 2010. Summarizing the evidence on the international trade in illegal wildlife. EcoHealth 7: 24-32.

Schurr MR, Fuentes A, Luecke E, et al. 2012. Intergroup variation in stable isotope ratios reflects anthropogenic impact on the Barbary macaques (Macaca sylvanus) of Gibraltar. Primates 53: 31-40.

Seddon PJ, Armstrong DP, and Maloney RF. 2007. Developing the science of reintroduction biology. Conserv Biol 21: 303-12.

Simberloff D, Martin J-L, Genovesi P, et al. 2013. Impacts of biological invasions: what's what and the way forward. Trends Ecol Evol 28: 58-66.

Sodhi NS, Koh LP, Brook BW, and Ng PKL. 2004. Southeast Asian biodiversity: an impending disaster. Trends Ecol Evol 19: 654-60.

Spalton JA, Lawrence MW, and Brend SA. 1999. Arabian oryx reintroduction in Oman: successes and setbacks. Oryx 33: $168-75$.

Stuart B, Nguyen TQ, Thy N, et al. 2012. Python bivittatus. The IUCN Red List of Threatened Species, version 2015.2. www. iucnredlist.org. Viewed 29 Nov 2016.

Tensen L. 2016. Under what circumstances can wildlife farming benefit species conservation? Global Ecol Conserv 6: 286-98.

Wiles GJ and Woodside DH. 1999. History and population of Guam swiftlets on O'ahu, Hawai'i. Elepiao 59: 57-61.

Zavaleta ES, Hobbs RJ, and Mooney HA. 2001. Viewing invasive species removal in a whole-ecosystem context. Trends Ecol Evol 16: 454-59.

Zhigang J and Harris RB. 2008. Elaphurus davidianus. The IUCN Red List of Threatened Species, version 2015.2. www.iucnre dlist.org. Viewed 29 Nov 2016.

\section{Supporting Information}

Additional, web-only material may be found in the online version of this article at http://onlinelibrary. wiley.com/doi/10.1002/fee.1449/suppinfo 